\title{
НЕКОТОРЫЕ ОСОБЕННОСТИ БИОЭЛЕКТРИЧЕСКОЙ АКТИВНОСТИ ГОЛОВНОГО МОЗГА ДЕТЕЙ С СИНДРОМОМ ДЕФИЦИТА ВНИМАНИЯ И ГИПЕРАКТИВНОСТИ
}

\author{
1 Дадашева К.Г. ${ }^{*}$ Мехтиева А.А. ${ }^{3}$ Агаева Г.Т. \\ ${ }^{1}$ Институт Физиологии им. А.И.Караева НАНА, Баку; \\ ${ }^{2}$ НИИ Педиатрии им. К.Я.Фараджсевой, Баку; \\ ${ }^{3}$ Азербайджанский Медищинский Университет, Баку
}

Ключевые слова: гиперактивность, биоэлектрическая активность мозга.

B число актуальных медико-биологических проблем относится синдром дефицита внимания и гиперактивности у детей 6-10 лет.

Синдром дефицита внимания с гиперактивностью (СДВГ) - поведенческое расстройство, относящееся к категории гиперкинетических расстройств (рубрика Ф90 по Международной классификации болезней, рубрика 314 по DSM-IV-TR, используемой Американской психиатрической ассоциацией), диагностируемое преимущественно у детей, характеризующееся триадой симптомов: нарушением внимания, гиперактивностью и импульсивностью. В современных эпидемиологических исследованиях, проведенных за рубежом, приводятся данные о распространенности СДВГ в детской популяции от $2 \%$ до $12 \%$ (в среднем $3-7 \%$ ) и имеющейся тенденция к росту их численности, в особенности у детей с пограничными расстройствами, которая варьирует в пределах 40-50\% (1-3). Это связано прежде всего с ростом пре- и постнатальных факторов. Многие авторы в своих исследованиях отмечают влияние патологических беременностей и родов, нарушений раннего онтогенеза на формирование в последующем церебральных отклонений (4).

В то же время по современным представлениям генетическая предрасположенность синдрому дефицита внимания и гиперактивности отмечается до $70 \%$ среди случаев болезни $(5,6)$.

По данным большинства современных авторов, изучающих проблему СДВГ, у детей с *email:kdadasheva@inbox.ru этим расстройством отмечается ряд особенностей строения и функционирования структур мозга; преимущественно это касается изменений со стороны префронтально-стриато-таламо-кортикальных структур. Исследования методом магнитно-резонансной томографии (МРТ), проведенные с использованием сравнительного морфометрического анализа головного мозга здоровых и страдающих СДВГ детей, позволили выявить у последних несколько меньшие размеры общего объема головного мозга, префронтальных отделов лобных долей головного мозга (особенно в правом полушарии), хвостатого ядpa, а также мозолистого тела, особенно в областях колена и валика, где проходят волокна, связывающие лобные, затылочные, височные и теменные доли. Кроме того, в литературе имеются свидетельства нарушения асимметрии определенных отделов головного мозга, которая характерна для нормального головного мозга (например, право-левой асимметрии полушария и подкорковых узлов). При исследованиях с применением методов функциональной нейровизуализации у детей с СДВГ показано снижение локального мозгового кровотока в лобной коре и подкорковых узлах. Данные, полученные методом позитронно-эмиссионной томографии (ПЭТ), указывают на снижение метаболической активности (снижение потребления глюкозы) в базальных ганглиях и префронтальной коре и повышение метаболической активности в сенсомоторных областях. Однако, при СДВГ перечисленные отклонения затрагивают тонкие структурные и 
функциональные элементы мозга и обнаруживаются не у всех пациентов. Несмотря на то, что эти отклонения не могут быть использованы для диагностических целей, их изучение помогает исследователям лучше понять нейробиологические основы СДВГ, его этиологию и патогенез. Общим для всех этих детей является снижение компенсаторно-приспособительных реакций организма к различным стрессовым факторам, в том числе и обучению в школе.

Методика. Нами было обследовано 54 ребенка в возрасте от 7 до 9 лет, учащиеся начальных классов общеобразовательных школ с жалобами родителей на повышенную утомляемость, гиперактивность, трудности обучения в школе, нарушения сна. Использовалась методика анкетного опроса и глубокого интервью с родителями по М.М.Безруких. У 43 детей был отягощен акушерский анамнез: неблагоприятное течение предыдущих беременностей, включающие метворождение, выкидыши, преждевременные роды, угроза прерывания беременности у 36 матерей, токсикозы первой и второй половины у 31 матери, перенесенные во время беременности матерями ОРВИ, особенно в первом триместре (22), требующая медикаментозной коррекции анемия у 12 женщин. Кесарево сечение было проведено 33 роженицам, в асфиксии родились 21 новорожденный, с гемолитической болезнью новорожденных 8.

46 детей до одного года наблюдались у невропатолога по поводу синдорома повышенной нервно-рефлекторной возбудимости, у 13 отмечены аффективно-респираторные пароксизмы. Исследуемые дети были подразделены на две группы : 1) успешно справляющиеся с программой $(26), 2)$ имеющие школьные трудности (дисграфия, дислексиия, дефицит внимания) (28). Рутинное электроэнцефалографическое исследование проводилось с помощью компьютерного электроэнцефалографа «НЕЙРОНСПЕКТР/4ВП». Расположение мостиковых электродов по международной системе 1020, запись в полосе частот: нижняя граница- постоянная во времени 0,1 с, верхняя граница 50 Гц. Запись осуществлялась монополярно и биполярно. Проведен сравнительный анализ спектров мощности по следующим диапазонам: 1) дельта диапазон (14Гц); 2) тета-диапазон 4-7 Гц; 3) альфа-диапазон (8-13 Гц); 4) бета диапазон (13-25 Гц). Параметры вычисления спектра: эпоха анализа 4 секунды, полуперекрывание эпох 50 $\%$, временное окно Хеннинга, длительность анализируемого фрагмента ЭЭГ в покое при закрытых глазах 1 минута. Достоверность различий представленных типов ЭЭГ по группам детей определяли с помощью т критерия. Для оценки межполушарной ассиметрии вычислялись разность мощности спектров по основным ЭЭГ диапазонам: тета-диапазон (4-7 Гц), альфа-диапазон (8-12 Гц), бета-диапазон (13-25 Гц) у детей имеющим трудности в обучении по сравнению с детьми успешно спавляющимися с программой. Достоверность различий оценивалась с помощью т-критерия Стьюдента.

Результаты исследований и их обсуждение. Сравнительный анализ ЭЭГ у обследованних нами детей выявил следующие достоверные различия. Спектры мощность альфа ритма у детей первой группы выше в фоне при закрытых глазах в затылочно-височных отделах обеих полушарий, при открытых глазах в обеих лобных и правой височной области. У детей успешно обучающихся в школе зрелый тип ЭЭГ (с затылочным фокусом альфа -ритма) как высокой, так и низкой амплитуды составлял $88 \%$, в то время как у детей имеющих трудности в обучении составлял $61 \%$. В ряду альфа-ритма заостренные формы по затылочно-височным отделам (чаще с левополушарным фокусом) у детей из первой группы встречались в 17\% случаев, в то время как у второй группы - в 30\% случаев (рис.1). У детей с разным уровнем развития достоверные различия в альфа- диапазоне с наибольшими изменениями по затылочным областям, можно расценивать как критерий зрелости/незрелости биоэлектрической активности головного мозга (7). 


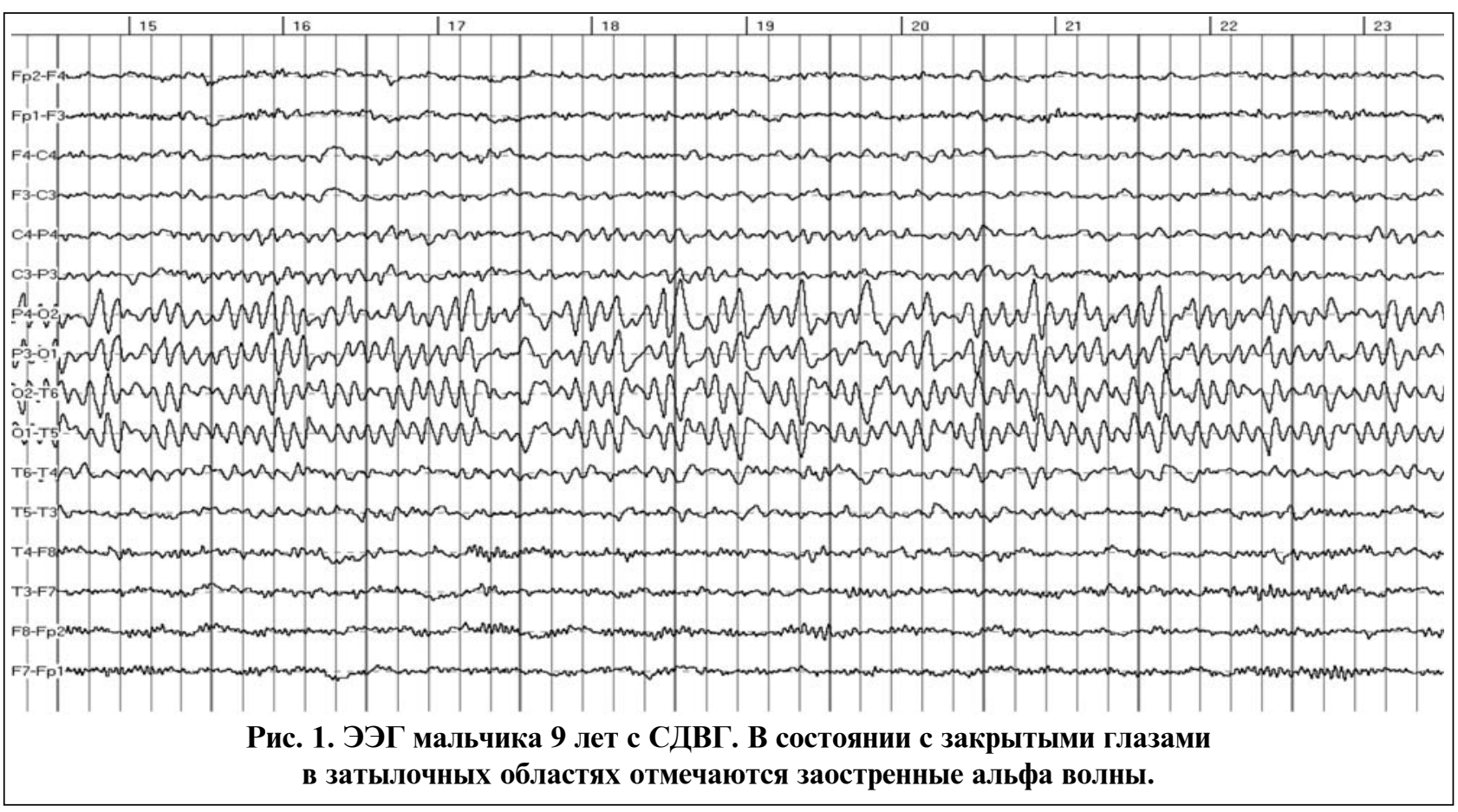

Спектры мощности в тета-диапазоне при закрытых глазах в левой лобной и височной области были значительно выше у детей второй группы по сравнению с первой. В фоне с открытыми глазами значения спектральной мощности тета- ритма в правой лобно-центральной превалировали у детей успешно справляющихся со школьной программой. В целом у детей обоих групп при открытых глазах во всех корковых областях отмечается уменьшение спектральной мощности тета-ритма. Подобный рост тета-ритма - эта типичная незрелая реакция активации, и как правило, коррелирует с эмоциольным состоянием $(6,7)$.

Более высокие значения спектральной мощности в бета-диапазоне отмечались у детей с трудностями обучения, кроме левой лобно-центральной области при закрытых глазах. Известно, что в бета-дипазоне выделяется более обширная система связей в левом полушарии (1). При открытых глазах в лобно-височных и центральных областях значения спектральной мощности в данном диапазоне частот ЭЭГ выше у детей успешно обучающихся, кроме затылочных областей, где напротив высокие показатели были у детей второй груп- пы. Ряд исследователей указывают на роль ассоциативной (а именнно лобной) формации коры мозга в организации поведения ребенка, в том числе такой его формы, как «спокойное бодрствование» $(9,10,11)$.

В затылочных отведениях у 3 детей, успешно справляющихся со школьной программой и у 9 детей, имеющих трудности обучения отмечались высокоамплитудные комплексы пик-волна (ДЭНД), блокирующаеся при открывании глаз, при сохранной основной активности. Это говорит о патогенетическом воздействии на головной мозг длительно персистирующей эпиактивности типа ДЭНД, даже в условии отсутствии приступов. Все 12 детей - это извлеченные путем кесарева сечения. СДВГ- частое следствие перинатальной, в большинстве случаев ишемической патологии .

Заключение: Снижение спектральной мощности по основным частотам ЭЭГ в левой гемисфере у детей второй группы указывает на уязвимость левого полушария под действием факторов перинатальной патологии, т.к. основным критерием для оценки степени зрелости биоэлектрической активности головного мозга у детей является сформированность альфа-ритма. 


\section{ЛИТЕРАТУРА:}

1. Gillberg C. Clinikal Child Neuropsychiatry.Cambridge UK: Cambridge University Press, 1995.366 p

2. Заваденко Н.Н. Гиперактивность и дефицит внимания в детском возрасте.Учебное пособие для студентов ВУЗов.М.: Изд.Дом «Школа-Пресс 1», 2001, $128 \mathrm{c}$.

3. McGough J.J.,Barkley R.A. Diaqnostic controversies in adult attention deficit hiperaktivity disorder|//Am.J.Psychiatry, 2004,V.161, №11, P.1948.

4. Студеникин В.М., Балаканская С.В., Шелковский В.И. Синдром дефицита внимания и гиперактивности у детей: диагностика и лечение./Лечащий врач, №1, 2010, С.31-34

5. Barr C.L., Feng Y., Wigg K. et al. SNAP-25 and attention deficit hiperaktivity disorder//Amer.J.Med.Genet., 2000, V.96, №4, P.490.

6. Barkley R.A. International consensus statement on ADHD//Clin.Child.Fam. Psychol.Rev., 2002,V.5, P.89-111

7. Кожушко Н.Ю., Пономарев В.А., Матвеев Ю.К., Евдокимов С.А. Возрастные особенности формирования биоэлектрической активности мозга у детей с отдаленными последствиями перинатального поражения ЦНС.//Физиология человека, 2011, том 37, №3, c.5-12

8. Klimesh W., Doppelmayr M., Wimmer H. et al.Theta band power changes in normal and dizlekxic children//Clin.Neurophysiol., 2001, V. 112(7), P.1174.

9. Безруких М.М., Теребова Н.Н. Функциональная организация коры больших полушарий головного мозга в состоянии покоя у детей 5,6 и 7 лет.//Физиология человека.2010, Т.36, №6, С.61.

10. Цехмистренко Т.А., Васильева В.А., Шумейко Н.С., Черных Н.А. Структурные преобразования коры большого мозга и мозжечка человека в постнатальном онтогенезе.// Развитие мозга и формирование познавательной деятельности/Под ред.Д.А.Фарбер, М.М.Безруких. М.:Изд-во МПСИ, Воронеж: Изд-во НПО «МОДЭК»,2009,С.9

11. Никитина Г.М. Основные теоретические подходы к изучению функциональной организации развивающегося мозга//Мозг и поведение младенца. М.: Ин-т психологии РАН,1993.С.3

12. Doose N.EEQ in chilthood epilepsy.Initial presentation and long-term follow-up//John Libbey, Hamburg, 2002-414P.).

\title{
XÜLASO
}

\section{DDHS OLAN UŞAQLARIN BAŞ BEYININININ BIOOELEKTRIKK AKTIVLIYINIIN BOZI XÜSUSIYYYTLORI}

\author{
${ }^{1}$ Dadasheva K.Q., ${ }^{2}$ Mehdiyeva A.A., ${ }^{3}$ Agayeva G.T. \\ ${ }^{1}$ AMEA-nin A.I. Karayev adına Fiziologiya İnstitutu, Bakı; \\ ${ }^{2}$ K. Faracova adına Elmi-Tadqiqat Pediatriya Institutu, Bakl; \\ ${ }^{3}$ Azarbaycan Tibb Universiteti, Bakl.
}

Bu işin məqsədi DçHS (diqqət çatmamazlığı və hiperaktivlik sindromu) olan uşaqlarda EEQnin əsas ritmlərinin spektral gücünün öyrənilməsi olub. Tədqiqatlarda iki qrupa, proqramın öhdəsindən müvəffəqiyyətlə gələn (I qrup) və məktəb çətinlikləri (disqrafiya, disleksiya, diqqət defisiti) olan (II qrup) 7-9 yaşlı 54 uşaq iştirak edib. Delta, teta, alfa və beta diapazonlar üzrə spektr gücünün müqaisəli analizi aparılıb. I qrupda fonda bağlı gözlər vəziyyətində alfa-ritmin spektral gücü hər iki yarımkürənin ənsə-gicgah nahiyələrində daha yüksəkdir. Bağlı gözlər vəziyyətində teta-diapazonun spektral gücü sol alın və gicgah nahiyələrdə II qrupda I qrupla müqaisədə əhəmiyyətli dərəcədə yüksəkdir. EEQ-nin əsas ritmlərinin spektral gücünün II qrupda sol hemisferdə enməsi, perinatal patologiyanın təsir amilləri altında sol yarımkürənin həssaslığına işarə edir, belə ki, uşaqlarda baş beyinin bioelektrik aktivliyinin yetkinlik səviyyəsinin qiymətləndirilməsinin əsas meyarı alfa-ritmin formalaşmasıdır.

Açar sözlər: hiperaktivlik, beynin bioelektrik aktivliyi. 


\title{
SUMMARY
}

\section{SOME PECULIARITIES OF THE BRAIN BIOELECTRICAL ACTIVITY AT CHILDREN WITH ADHD}

\author{
${ }^{1}$ Dadashova K.Q., ${ }^{2}$ Mehdieva A.A., ${ }^{3}$ Agaeva G.T. \\ ${ }^{1}$ Scientific Researcher Institute of Physiology of name A.I.Karaev, Baku; \\ ${ }^{2}$ Scientific Researcher Institute of Pediatric of name K.Farajova, Baku; \\ ${ }^{3}$ Azerbaijan Medical University, Baku.
}

The purpose of this study was to examine the spectral power of the EEG basic rhythms of children with ADHD (Attention Deficit Hyperactivity Disorder). The study involved 54 children of 7-9 years, who were divided into groups of children to cope successfully with the program (1) and having school difficulties (dysgraphia, dyslexia, attention deficit) (2). A comparative analysis of the power spectra in the delta, theta, alpha and beta bands. The spectral power of the alpha rhythm in the first group of children above the background with eyes closed in occipital-temporal areas of both hemispheres. The spectral power in the theta range with eyes closed in the left frontal and temporal regions were significantly higher in children of the second group as compared with the first. The decrease in spectral power at the main EEG frequencies in the left hemisphere of the second group of children points to the vulnerability of the left hemisphere under the influence of perinatal pathology factors, as the main criterion for assessing the maturity of brain activity in children is the formation of the alpha rhythm.

Key words: hyperactivity, brain bioelectrical activity.

Redaksiyaya daxil olub: 09.10.2012

Çapa tövsiyə olunub: 19.10.2012

Rəyçi: R.K.Şirəliyeva 